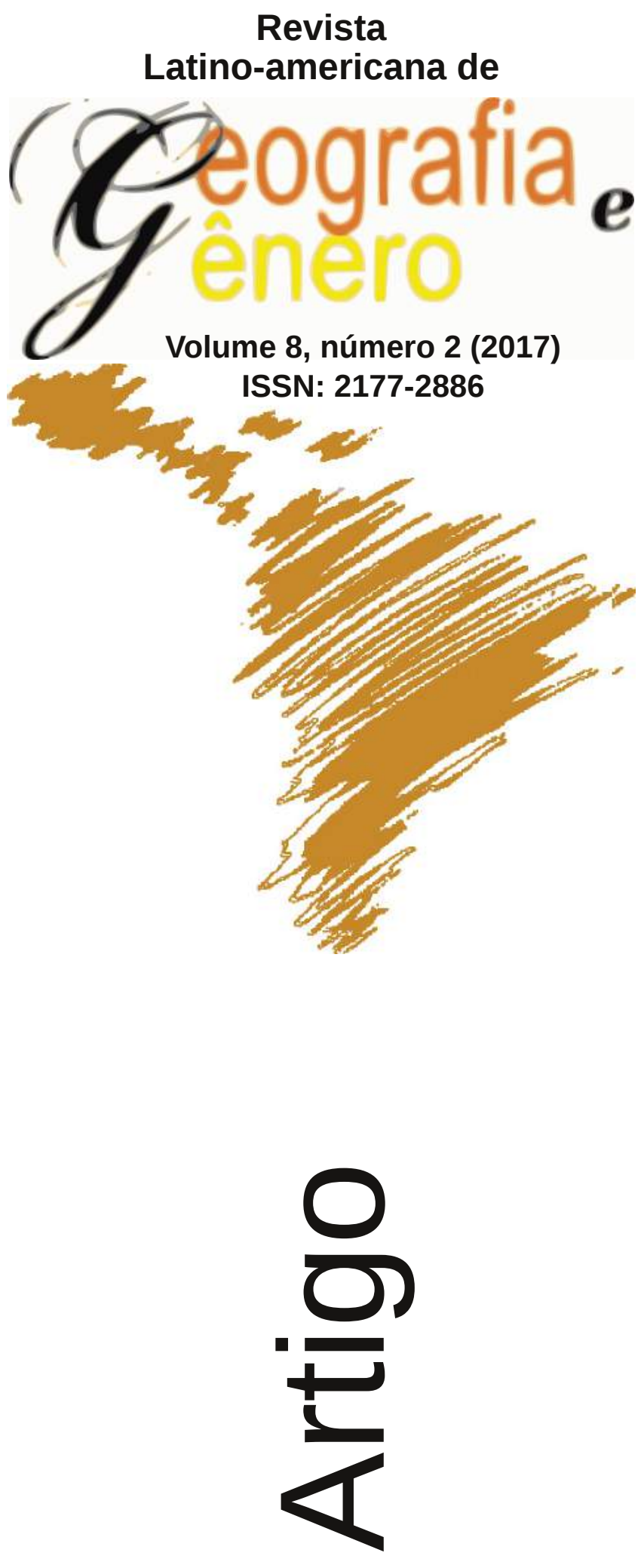

Desigualdades de Gênero nas Nomeações para Cargos de Gestão dos Hospitais Portugueses no Período de 2006 - 2016

Desigualdades de Género en los Nombramientos para Cargos de Gestión de los Hospitales Portugueses en el Período de 2006 2016

Gender Inequalities in the Appointment of Hospital Managers by the Portuguese Government in the Period 2006 - 2016

\begin{abstract}
Alexandre Morais Nunes
Instituto Superior de Ciências Sociais e Políticas - Universidade de Lisboa - Portugal anunes@iscsp.ulisboa.pt
\end{abstract}

Como citar este artigo:

NUNES, Alexandre Morais. Desigualdades de Gênero nas Nomeações para Cargos de Gestão dos Hospitais Portugueses no Período de 2006 a 2016. Revista Latino Americana de Geografia e Gênero, v. 8, n. 2, p. 168-182, 2017. ISSN 2177-2886.

Disponível em:

http://www.revistas2.uepg.br/index.php/rlagg 


\title{
Desigualdades de Gênero nas Nomeações para Cargos de Gestão dos Hospitais Portugueses no Período de 2006 - 2016
}

\author{
Desigualdades de Género en los Nombramientos para Cargos de Gestión de \\ los Hospitales Portugueses en el Período de 2006 - 2016
}

\author{
Gender Inequalities in the Appointment of Hospital Managers by the \\ Portuguese Government in the Period 2006 - 2016
}

\begin{abstract}
Resumo
O presente estudo tem como objetivo analisar as desigualdades de gênero nas nomeações do governo português para os altos cargos da direção hospitalar entre os anos 2002 e 2016. Estes são altos cargos da administração pública portuguesa com salários elevados. Os dados para o estudo foram extraídos dos diplomas legais de nomeação para cada hospital, centro hospitalar ou Unidade Local de Saúde. Os parâmetros descritivos e analíticos foram processados com recursos a métodos de estatística descritiva. Como resultados, constatou-se que existe uma diferenciação permanente nas nomeações com uma maior tendência, durante todo o período de tempo, para a maior nomeação de homens do que de mulheres, cerca $60,3 \%$ contra $39,7 \%$, respectivamente. Para entender melhor a diferença encontrada, foram realizadas entrevistas aos decisores políticos na área da saúde. Em conclusão, primeiro, os entrevistados referiram que há menos mulheres que homens disponíveis para estes cargos e, segundo, referiram que a liderança masculina é mais respeitada.
\end{abstract}

Palavras-Chave: Desigualdades; Homens; Mulheres; Gestão Hospitalar; Nomeações do Governo.

\section{Resumen}

Este estudio tiene como objetivo analizar las desigualdades de gênero en los nombramientos del gobierno portugués para los altos cargos de la dirección hospitalaria entre 2006 y 2016. Estos son altos cargos de la administración pública portuguesa con altos salarios. Los datos de fueron extraídos de los diplomas legales de nombramientos para cada hospital, centro hospitalario o unidad local de salud. Los parámetros descriptivos y analíticos fueron procesados utilizando métodos de estadística descriptiva. Como resultado, se encontró que existe una diferenciación permanente en nombramientos, con una mayor tendencia, a lo largo de todo el período de tiempo, hacia un mayor ombramiento de hombres que de mujeres, sobre un $60,3 \%$ contra un $39,7 \%$, respectivamente. Para entender mejor la diferencia encontrada, se realizaron entrevistas a los responsables políticos en materia de salud. En conclusión, en primer lugar, los encuestados mencionaron que hay menos mujeres que hombres disponibles para estos puestos y, en segundo lugar, dijeron que en los hospitales el liderazgo masculino es más respetado.

Palabras-Clave: Desigualdades; Hombres; Mujeres; Gestión Hospitalaria; Citas de Gobierno.

Alexandre Morais Nunes

Revista Latino-americana de Geografia e Gênero, Ponta Grossa, v. 8, n. 2, p. 168 - 182, ago. / dez. 2017. 


\begin{abstract}
This study aims to analyze gender inequalities in the appointment of hospital managers by the Portuguese government between 2002 and 2016. These positions are the top of Portuguese public administration, with high salaries. The data for this study were extracted from excerpts of the Portuguese Republic Diary, the journal that advertises the appointments for each hospital, hospital center or local health unit. The descriptive and analytical settings were processed with feature methods of descriptive statistics. As a result, it was found that there is a constant bias, with a higher tendency, in the considered period, of choosing men rather than women (about 60,3\% vs. 39,7\%, respectively). For a better understanding of this difference, we interviewed policy makers in healthcare. In conclusion, first, respondents mentioned that there were fewer women than men available for these positions, and second, the respondents said that in hospitals, male leadership is more respected.
\end{abstract}

Keywords: Inequalities; Men; Women; Hospital Management; Governmental Appointments.

\title{
Introdução
}

No mundo moderno e desenvolvido, homens e mulheres desempenham cargos em vários campos e setores de atividade, desde as mais altas às mais baixas posições profissionais. Contudo, a desigualdade entre gênero é ainda uma realidade que se vive nos dias de hoje.

Os estudos sobre a desigualdade de gênero são cada vez mais importantes para sinalizar alguma diferenciação entre homens e mulheres e contrariar a construção histórica que se desenvolveu até à conquista da emancipação identitária.

O impedimento ou a desvalorização das mulheres em relação aos homens é prejudicial ao desenvolvimento, à economia de um país e vai contra a tudo o que entendemos por construção social. Está em causa os direitos dos cidadãos, que não podem ser postos em causa em nenhum momento nem por qualquer causa, seja ela o gênero ou outras como a religião, a raça, a orientação sexual, ou o modo e as dificuldades em que se vive.

A administração pública portuguesa, desde o início do novo período democrático, iniciado em 1976, tem desenvolvido planos para promover a igualdade entre os cidadãos com o objetivo de eliminar as desigualdades entre mulheres e homens, nas suas estruturas, de forma a estabelecer a igualdade de direitos (Constituição da República Portuguesa, 1976).

$\mathrm{O}$ principio de igualdade, vigente em Portugal, está publicado na Constituição da República Portuguesa, no seu artigo $13^{\circ}$ e refere que: "todos os cidadãos têm a mesma dignidade social e são iguais perante a lei" e, ainda, refere que "ninguém pode ser privilegiado, beneficiado, prejudicado, privado de qualquer direito ou isento de qualquer dever em razão de ascendência, sexo, raça, língua, território de origem, religião, convicções políticas ou ideológicas, instrução, situação econômica ou condição social".

A União Europeia (EU), nos seus princípios gerais e valores, defendeu o princípio de igualdade entre os países que a integram e de todos os cidadãos dentro de cada país, falando-se de uma comunidade europeia, que cumpre 
|| normas e regras europeias. De acordo com a Carta de Convenção da União Europeia, o respeito pela dignidade humana, pela liberdade e pela igualdade e pelo respeito dos direitos do Homem são valores comuns e fundamentais. Assim, o lema da EU é de ir contra qualquer intolerância, injustiça ou discriminação pelo descumprimento destes valores, pelo que o descumprimento de qualquer uma destas condições pode conduzir à suspensão e expulsão de um país desta União (artigo I- $58^{\circ}$ da EU).

A EU financia planos para o desenvolvimento de políticas públicas de igualdade nos seus Estados-membros, incluindo Portugal, que se aplicam tanto no setor público como no privado, com o objetivo de integrar a igualdade de gênero de forma transversal como uma prática comum em todo os países (FERREIRA et al., 2013; MONTEIRO e FERREIRA, 2013).

A desvalorização e a desqualificação das mulheres em relação aos homens é a base da desigualdade de gênero. Apesar das indicações europeias e de constar na legislação portuguesa, a verdade é que há estudos que comprovam as desigualdades entre homens e mulheres no trabalho em pleno século XXI. Portugal não é exceção e há muito mais homens do que mulheres na administração pública portuguesa.

O tema principal que despoletou o desenvolvimento deste artigo se relaciona com a desigualdade nas nomeações dos hospitais. Para isso, se realizou uma análise documental dos vários diplomas legais (diplomas) de escolha para os cargos de gestão dos hospitais nos últimos 10 anos e, a partir deles, foram levantados os dados relativos ao gênero dos nomeados pelos sucessivos governos.

$\mathrm{Na}$ coleta de dados por gestor hospitalar se entende todos os nomeados para os cargos de Presidente do conselho de administração ou vogal executivo e não executivo (diretor clínico e enfermeiro diretor).

Foi dada evidência ao espaço temporal de dez anos, que totalizaram cinco governos de Portugal: XVII Governo Constitucional (2005-2009); o XVIII (2009-2011), o XIX (2011-2015), o XX (2015-2015) e o XXI (2015-atual). Uma vez coletados os dados, foi realizada uma análise estatística simples dos mesmos com recursos a métodos descritivos e, nas primeiras elações, se verificou que existe uma desigualdade de oportunidades, no que se refere às nomeações para os altos cargos de gestão hospitalar, o que penaliza as mulheres. A grande maioria dos nomeados para estes cargos é homem.

Face ao exposto, se pretendeu saber o porquê de as mulheres serem pouco nomeadas para estes lugares. Para responder a esta questão, foram realizadas entrevistas semiestruturadas aos dirigentes técnicos e políticos envolvidos nos processos de nomeação.

\section{As Conceções e a Histórica Desigualdade de Gênero na Sociedade}

As desigualdades entre gênero não são um achado do século XXI, pelo contrário, é já uma questão que se arrasta há vários séculos (MONTEIRO, 2005). Estas desigualdades traduzem o fato de homens e mulheres não terem acesso às mesmas oportunidades (OAKLEY, 1972).

A evolução histórica condicionou a emancipação da mulher que, apesar de 
se ter realizado, ainda é uma realidade não aceita por várias sociedades (MONTEIRO, 2005). As relações de gênero geraram, ao longo do percurso histórico, uma distinção entre homens e mulheres fundada no prestígio, na relação de poder, nas oportunidades na sociedade, no maior prestigio e na maior segurança e fidelidade. Estas questões limitaram a liberdade das mulheres, já que todos os imperativos associados ao poder e influência social estiveram sempre, historicamente, vinculados ao gênero masculino (ACKER, 1992; AMÂNCIO, 1994; MONTEIRO, 2005). De acordo com Bourdieu (2002), todas as pessoas têm um conjunto de características particulares como o gênero, a raça, a religião, a cor, a profissão, a escolaridade e o salário e, a sociedade faz uma distinção entre os cidadãos que apresentam estas características, diferenciando os indivíduos, o que gera muitas desigualdades.

É interessante observar o poder do contexto social em separar o que é característico e permitido ou vetado ao gênero masculino e, por outro lado, o que é obrigação ou proibição do gênero masculino. Repare-se no contexto de desigualdade nas palavras aplicadas (o que é característico ou função do homem e o que é obrigação ou proibição da mulher) que marcam, à partida, logo uma distinção das funções sociais.

Além disso, as desigualdades e a discriminação das mulheres, ao longo da história, foram muito além do gênero, foram influenciadas pelo status social (mulher de famílias ou pai poderoso vs. mulher pobre ou de família tradicional); raça (mulher negra vs. mulher branca); idade (mulher mais nova ou a mulher envelhecida).

As mulheres, logo a partida, pelo seu gênero sexual, já tinham um ponto a favor da discriminação e da desigualdade de oportunidades. Para agravar estes se juntavam os aspetos negativos, como a baixa renda, a raça negra, a baixa escolaridade, a fraca força de trabalho (MONTEIRO, 2005).

Simultaneamente com a discriminação do papel social e político da mulher, foram socialmente atribuídas outras funções mais relacionadas com o seu papel familiar, com as emoções e com a componente relacional. Assim, a mulher foi vista durante muitos anos como mulher (dona de casa), filha (que participa nas atividades da casa ajudando sua mãe a tratar de seu pai e irmãos), mãe (gerando, criando e educando os seus filhos), organizadora do ambiente doméstico (em que após casar organiza a casa e prepara tudo o que o marido precisar, desde a roupa à alimentação). Por outro lado, eram também definidas as práticas sociais consentâneas com a representação da figura masculina (AMÂNCIO, 1994). Dessa forma, o homem desempenhava o papel de domínio político, representante da lei e da causa pública, responsável pelo sustento de sua família e era visto como um sinal de força e de domínio (ABOIM, 2007, 2010; AMÂNCIO, 1994).

A redefinição do papel da mulher passou por uma mudança estrutural, social que enquadrou a mulher na vida social e originou uma nova divisão do trabalho. $\mathrm{Na}$ emancipação e empoderamento da mulher foram reivindicado o direito à cidadania política e social e o direito à participação no mundo do trabalho, com acesso a um salário, a direitos trabalhistas e à cidadania, podendo votar como qualquer homem e participar na vida política ativa, elegendo e sendo elegíveis e, consequentemente, eleitas.

O papel historicamente associado à mulher nas suas tarefas domésticas e na

Alexandre Morais Nunes 
1| educação dos filhos continuou mesmo após a emancipação. Para além do esforço feminino associado a uma vida social, politica e profissional ativa, as mulheres ainda sobrecarregam as funções domésticas.

Apesar da emancipação da mulher e da sua participação mais ativa na sociedade e no mercado de trabalho, a verdade é que em pleno seculo XXI, continua a existir uma diferenciação dos papéis desempenhados por homens e mulheres. Por um lado, nas funções desempenhadas e pela retribuição salarial (LONGO, 2011).

No mundo do trabalho, passou a existir uma divisão entre as funções/papéis femininos e masculinos, continuando a se admitir uma assimetria entre os gêneros, ou seja uma desigualdade (LONGO, 2011). Eram considerados trabalhos de mulheres as funções de prestação de cuidados de saúde, as funções administrativas, as funções de limpeza, as funções de ensino/educação, os trabalhos de cozinha, na indústria do vestuário, entre outras. E, eram considerados trabalhos de homens: a construção, os cargos políticos, financeiros, médicos, fabris, agricultura e todos os trabalhos de gestão e organização da sociedade, onde se incluem os cargos de administração dos serviços públicos.

No entanto, embora as mulheres tivessem trabalho, existia uma desigualdade na qualificação do emprego e o valor dos salários das mulheres eram discriminados relativamente ao dos homens (LONGO, 2011). Estava vetado o acesso das mulheres a funções dirigentes com níveis remuneratórios superiores. Ou seja, uma mulher independentemente do seu trabalho desenvolvido não podia ganhar mais salário que um homem.

De acordo com Santos (2010), os estereótipos em torno do sexo feminino, marcaram as desigualdades entre homens e mulheres, relacionando erroneamente, a feminilidade da mulher com uma limitação para as suas ações, comportamentos e atitudes, o que no pensamento da sociedade contrariam todos os pré-requisitos para uma carreira na gestão e na decisão política.

Para além da questão relacionada com o processo de socialização, Santos (2010) refere, ainda, que existia o entendimento que os traços de personalidade das mulheres e as suas motivações intrínsecas poderiam condicionar o acesso às redes informais e aos grupos dominantes da estrutura de poder. Por fim, o mesmo autor, no seu estudo, ainda referiu que a neutralidade do gênero pode ser um fator não controlado no sexo feminino que esteve muitos anos limitado e sem poder na sociedade e presença no mercado de trabalho.

\section{Desigualdade de Gênero na Administração Pública Portuguesa}

A desigualdade de gênero no trabalho, sendo uma construção social, decorreu de uma forma geral em todos os setores de atividade, independentemente da propriedade ou titularidade das instituições/empresas ser pública ou privada.

Em Portugal, a distribuição dos empregos por gênero, desde a implementação da última República, até ao ano 2015, apresenta-se na seguinte tabela: 
Desigualdades de Gênero nas Nomeações para Cargos de Gestão dos

Hospitais Portugueses no Período de 2006 a 2016

Tabela 1 - População empregada em Portugal (em milhares).

\begin{tabular}{|c|c|c|c|}
\hline \multirow{2}{*}{ Anos } & \multicolumn{3}{|c|}{ Sexo } \\
\hline & Total & Masculino & Feminino \\
\hline 1974 & $3.694,0$ & $2.227,5$ & $1.466,5$ \\
\hline 1975 & $3.724,0$ & $2.280,0$ & $1.444,0$ \\
\hline 1976 & $3.789,0$ & $2.332,5$ & $1.456,5$ \\
\hline 1977 & $3.784,0$ & $2.331,0$ & $1.453,0$ \\
\hline 1978 & $3.772,0$ & $2.339,5$ & $1.432,5$ \\
\hline 1979 & $3.853,0$ & $2.357,0$ & $1.496,0$ \\
\hline 1980 & $3.924,5$ & $2.400,5$ & $1.524,0$ \\
\hline 1981 & $3.969,0$ & $2.386,5$ & $1.582,5$ \\
\hline 1982 & $3.958,5$ & $2.375,5$ & $1.583,0$ \\
\hline 1983 & $4.352,5$ & $2.637,5$ & $1.715,0$ \\
\hline 1984 & $4.288,1$ & $2.588,0$ & $1.700,1$ \\
\hline 1985 & $4.269,5$ & $2.562,6$ & $1.706,9$ \\
\hline 1986 & $4.289,1$ & $2.569,0$ & $1.720,1$ \\
\hline 1987 & $4.405,8$ & $2.601,9$ & $1.803,9$ \\
\hline 1988 & $4.512,8$ & $2.639,3$ & $1.873,6$ \\
\hline 1989 & $4.613,1$ & $2.688,8$ & $1.924,4$ \\
\hline 1990 & $4.717,5$ & $2.723,7$ & $1.993,8$ \\
\hline 1991 & $4.857,4$ & $2.764,3$ & $2.093,2$ \\
\hline 1992 & $4.543,1$ & $2.548,7$ & $1.994,4$ \\
\hline 1993 & $4.457,7$ & $2.486,0$ & $1.971,6$ \\
\hline 1994 & $4.449,2$ & $2.472,7$ & $1.976,4$ \\
\hline 1995 & $4.415,9$ & $2.447,5$ & $1.968,4$ \\
\hline 1996 & $4.444,9$ & $2.458,9$ & $1.986,0$ \\
\hline 1997 & $4.530,4$ & $2.495,8$ & $2.034,6$ \\
\hline 1998 & $4.848,4$ & $2.694,7$ & $2.153,7$ \\
\hline 1999 & $4.925,7$ & $2.715,2$ & $2.210,5$ \\
\hline 2000 & $5.041,3$ & $2.774,6$ & $2.266,7$ \\
\hline 2001 & $5.128,2$ & $2.816,1$ & $2.312,1$ \\
\hline 2002 & $5.143,8$ & $2.814,1$ & $2.329,7$ \\
\hline 2003 & $5.093,4$ & $2.763,1$ & $2.330,3$ \\
\hline 2004 & $5.062,3$ & $2.736,5$ & $2.325,8$ \\
\hline 2005 & $5.047,3$ & $2.706,8$ & $2.340,6$ \\
\hline 2006 & $5.079,0$ & $2.725,1$ & $2.354,0$ \\
\hline 2007 & $5.092,5$ & $2.725,2$ & $2.367,3$ \\
\hline 2008 & $5.116,6$ & $2.725,3$ & $2.391,3$ \\
\hline 2009 & $4.968,6$ & $2.611,7$ & $2.356,9$ \\
\hline 2010 & $4.898,4$ & $2.569,3$ & $2.329,1$ \\
\hline 2011 & $4.740,1$ & $2.487,2$ & $2.252,9$ \\
\hline 2012 & $4.546,9$ & $2.357,3$ & $2.189,6$ \\
\hline 2013 & $4.429,4$ & $2.288,4$ & $2.141,0$ \\
\hline 2014 & $4.499,5$ & $2.319,5$ & $2.180,0$ \\
\hline 2015 & $4.548,7$ & $2.334,3$ & $2.214,4$ \\
\hline
\end{tabular}

Fonte: Instituto Nacional de Estatística de Portugal (INE, 2016). 
A população empregada em Portugal sempre foi majoritariamente masculina, existindo uma desigualdade para as mulheres. No entanto, a assimetria tem vindo a ser reduzida. No final dos anos 1970, antes da revolução portuguesa, de 25 de abril de 1975 (que terminou com um regime ditatorial), a proporção de mulheres a trabalhar era somente de 39,7\%. No final da década de 1970, essa taxa passou baixou para 38,7\%, e dez anos mais tarde esta taxa cresceu para $41,7 \%$. No ano 2000 , a proporção de mulheres empregadas atingiu os $45 \%$ e, atualmente, no ano de 2015 , temos uma total de $48,7 \%$, praticamente o mesmo que no gênero masculino. Isto significa que o tradicional modelo de ganha-pão masculino não é tão forte em Portugal.

As assimetrias de gênero foram, também, verificadas na administração pública. Apesar de no setor público as mulheres serem integradas em trabalhos no âmbito dos setores da saúde, educação, de atendimento ao público e em serviços de limpeza/manutenção dos espaços e das estruturas, houve uma diferenciação relativamente aos homens sobretudo nas variáveis sócioorganizacionais (RATO et al., 2007).

$\mathrm{Na}$ administração pública, as maiores desigualdades de gênero se manifestaram na forma como se organizou e estruturou o trabalho, na gestão dos tempos, nos atributos e nos requisitos exigidos e, também, na forma como se progredia nas carreiras profissionais (MONTEIRO, 2012). Por exemplo, apesar de as mulheres estarem em maioria, a sua representatividade é dominante nos cargos de execução e direção intermédia, sem poder de decisão (PERNAS, FERNANDES e GUERREIRO, 2008).

A forte participação das mulheres na Administração Pública, em Portugal, pode indicar uma tendência para a mudança de papéis e valores do gênero, Contudo, nesse mesmo ano 2015, o ganho médio mensal de uma mulher é de $963,1 € /$ mês e de um homem é de $1.203,3 € /$ mês, o que significa uma diferenciação na seleção de mulheres para os cargos melhor remunerados, mas não de topo, sendo a maioria dos dirigentes superiores da administração pública do sexo masculino (64\%) e apenas 36\% do feminino. As diferenças salariais ilustram as desigualdades de gênero (BASTOS, et. al., 2007).

No ano 2013, para tornar mais transparente o processo de nomeação de altos dirigentes e combater a desigualdade de acesso, incluindo a motivada pela desigualdade de gênero, foi criada uma comissão externa de recrutamento, conhecida como CReSAP (Comissão de Recrutamento e Seleção para a Administração Pública).

A CReSAP, em nome da boa governança, foi um processo inovador na Administração Pública portuguesa que tinha como objetivo assegurar com transparência, com isenção, com rigor e de forma independente a seleção dos dirigentes de topo. Com esta estrutura, a alta direção da Administração Pública portuguesa passou a ser nomeada através de um sistema meritocrático, com base no mérito individual e não em função ou restrição do gênero, da opção política, dos grupos de interesse, da religião ou da raça. Pelo contrário, são identificadas e valorizadas as capacidades de todos os candidatos.

\section{Cargo de Gestor Hospitalar}

O setor da saúde é um setor particular na Administração Pública portuguesa, 
pois consome milhares de milhões em recursos e, por este motivo, existe uma pressão nos gestores para promover o controle financeiro que contribua para a garantia da sustentabilidade do Serviço Nacional de Saúde aberto a todos os cidadãos (NUNES, 2013).

Os hospitais são os principais consumidores de recursos no setor público da saúde. Cabe aos administradores hospitalares atingir os objetivos de produção propostos dentro do cabimento orçamental atribuído pelo Estado (HARFOUCHE, 2012; NUNES, 2016). Para a concretização dos objetivos de gestão, o individuo que ocupa o cargo de gestor hospitalar deve ter a capacidade de envolver toda a estrutura, motivando os profissionais de saúde, orientar a organização, munir-se de ferramentas de gestão e de controle, promovendo o acesso, a eficiência e a qualidade com o objetivo de gerar valor para os utentes/doentes (NUNES, 2013, 2016).

Os gestores hospitalares, por um lado, podem integrar os conselhos de administração de hospitais, centros hospitalares (repartição de uma mesma equipe de gestão para dois ou mais hospitais) e unidades locais de saúde (repartição de uma equipe de gestão com a atenção primária e um hospital). Por outro lado, os gestores hospitalares, dentro do conselho de administração podem assumir a função de presidente (líder da equipe), vogal (responsável pela prestação gestão financeira e/ou operacional), diretor clínico (gestor responsável pela atividade clínica - este é um médico de formação base) e enfermeiro diretor (gestor responsável pela atividade de enfermagem enfermeiro de formação base).

De acordo com Campos (2008), a seleção de gestores hospitalares deve ser muito cuidadosa e a inclusão de gestores de fora da área da saúde no desempenho de cargos de gestão hospitalar pode trazer inovação e fertilização cruzada, mas, perdem por desconhecerem da especificidade do setor.

Em linha com o exposto, em Portugal, a nomeação dos gestores públicos, onde se enquadram os administradores/gestores hospitalares, desde 2013, com a implementação da CReSAP, passou-se a ter em conta um conjunto de doze critérios, a referir:

- Aptidão para o Cargo: grau de conhecimentos da empresa/organização de destino e capacidade para distinguir o essencial do acessório;

- Liderança: maior ou menor capacidade de cada um para influenciar o comportamento e atitude de outros em contexto organizacional;

- Colaboração: capacidade de abertura aos outros (pessoas, grupos ou organizações - públicas, privadas, terceiro setor); gosto pelo trabalho em equipe;

- Motivação: os fatores endógenos são mais valorizados (interiores à própria pessoa) tais como o próprio interesse pelos desafios do trabalho e a realização pessoal;

- Orientação Estratégica: preocupação com o futuro por oposição ao cotidiano. Colocar o hoje em função do que deverá ser o amanhã. A visão futura da organização condiciona o seu presente;

- Orientação para Resultados: forte determinação na obtenção de resultados, metas e objetivos. Urgência na ação, desafia os outros e a si próprio;

- Orientação para o Cidadão e Serviço de Interesse Público: forte envolvimento na prestação de um serviço de qualidade em particular nos 
setores onde a empresa atua;

- Gestão da Mudança e Inovação: fraca adesão à conformidade oferecida pelas normas e regras e, pelo contrário, forte adesão ao risco calculado, à inovação e ao desafio constantes do cotidiano;

- Sensibilidade Social: forte preocupação com a responsabilidade social da empresa, em particular, pelos efeitos no ambiente. Preocupação com as consequências das decisões;

- Experiência Profissional: possuir trajeto profissional, no mínimo de 12 anos;

- Formação Acadêmica: qualidade da formação; classificação final; quantidade de formação formal; relação entre o conteúdo da formação, o trajeto profissional e o lugar em causa;

- Formação Profissional: valorizar muito a adequação/relação entre a formação profissional específica obtida e o zigue-zague do trajeto profissional (CReSAP, 2016).

Além dos critérios indicados, é considerada uma avaliação comportamental onde são avaliadas características como: a capacidade para antecipar consequências; a criatividade; a determinação; a resiliência; a flexibilidade; a empatia; a capacidade para lidar com a ambiguidade; a orientação para os procedimentos; a atenção concentrada; a tecnicidade; a adaptabilidade e a atenção ao detalhe (CReSAP, 2016).

\section{Método}

Para apurar o número de nomeações de homens e mulheres para os cargos de gestão hospitalar, realizados em Portugal, recorreu-se à análise documental dos diplomas legais que nomeiam a constituição dos conselhos de administração dos hospitais empresa entre os anos 2006 e 2016.

$\mathrm{Na}$ coleta destes dados, se teve em atenção os vários períodos temporais correspondentes a diferentes governos da República, pois, por norma, sempre que um governo assume funções são efetuadas novas nomeações.

Para analisar os resultados obtidos pela coleta de dados, é realizada uma análise estatística simples, calculando os totais de nomeações, por cargo desempenhado.

Em seguida, para determinar os fatores que estão na base das diferenças obtidos entre o número de mulheres e homens nomeados para os cargos de gestão hospitalar, foram efetuadas 30 entrevistas aos principais atores políticos e das estruturas do Ministério da Saúde diretamente envolvidos nos processos de nomeação, com o objetivo de saber o que estará por trás da desigualdade de acesso a estes altos cargos da Administração Pública. Assim, foram colocadas quatro questões aos entrevistados:

1. Considera que houve desigualdade de gênero nas nomeações para os cargos de gestão hospitalar nos últimos 10 anos?

2. Quais as razões que encontra para o fato de haver mais homens ou mulheres nomeados?

3. O poder político tem influência direta na decisão? Em que base 
Desigualdades de Gênero nas Nomeações para Cargos de Gestão dos

Hospitais Portugueses no Período de 2006 a 2016

fundamenta a sua resposta?

4. A CReSAP melhorou a imparcialidade nas nomeações? Justifique?

As respostas obtidas foram operacionalizadas com recurso ao método da análise de conteúdo. Foram considerados, neste estudo, os princípios de confidencialidade e ao anonimato, sendo sempre preservada a identidade dos participantes na entrevista ao expressarem a sua opinião.

\section{Resultados}

Os resultados obtidos pela coleta de informação relativa ao gênero nas nomeações para cargos de administração hospitalar no setor público português são apresentados na tabela 2, de acordo com a tipologia do hospital empresa (hospital, centro hospitalar ou unidade local de saúde) e na tabela 3 em função do cargo desempenhado (existem quatro cargos diferentes para os gestores hospitalares: o de presidente, o de vogal, o de diretor clínico e o de enfermeiro diretor).

Tabela 2 - Distribuição dos gestores hospitalares nomeados por tipologia de hospital.

\begin{tabular}{|c|c|c|c|c|c|c|c|c|c|c|}
\hline & \multicolumn{2}{|c|}{$2006-2009$} & \multicolumn{2}{|c|}{ 2009-2011 } & \multicolumn{2}{|c|}{ 2011-2015 } & \multicolumn{2}{|c|}{ 2015-2015 } & \multicolumn{2}{|c|}{ 2015-atual } \\
\cline { 2 - 11 } & $\mathrm{M}$ & $\mathrm{H}$ & $\mathrm{M}$ & $\mathrm{H}$ & $\mathrm{M}$ & $\mathrm{H}$ & $\mathrm{M}$ & $\mathrm{H}$ & $\mathrm{M}$ & $\mathrm{H}$ \\
\hline Hospitais & 59 & 71 & 25 & 36 & 17 & 32 & 17 & 32 & 16 & 33 \\
\hline $\begin{array}{c}\text { Centros } \\
\text { Hospitalares }\end{array}$ & 33 & 52 & 34 & 59 & 38 & 60 & 38 & 60 & 43 & 55 \\
\hline $\begin{array}{c}\text { Unidade } \\
\text { Local de } \\
\text { Saúde }\end{array}$ & 9 & 15 & 17 & 24 & 16 & 23 & 16 & 23 & 15 & 24 \\
\hline Total & 101 & 138 & 77 & 119 & 71 & 115 & 71 & 115 & 74 & 112 \\
\hline
\end{tabular}

Fonte: Elaboração própria com base nas nomeações publicadas em Diário da República.

Tabela 3 - Distribuição dos gestores hospitalares nomeados por cargo desempenhado.

\begin{tabular}{|c|c|c|c|c|c|c|c|c|c|c|}
\hline & \multicolumn{2}{|c|}{$2006-2009$} & \multicolumn{2}{|c|}{$2009-2011$} & \multicolumn{2}{|c|}{ 2011-2015 } & \multicolumn{2}{|c|}{ 2015-2015 } & \multicolumn{2}{|c|}{ 2015-atual } \\
\cline { 2 - 12 } & $\mathrm{M}$ & $\mathrm{H}$ & $\mathrm{M}$ & $\mathrm{H}$ & $\mathrm{M}$ & $\mathrm{H}$ & $\mathrm{M}$ & $\mathrm{H}$ & $\mathrm{M}$ & $\mathrm{H}$ \\
\hline Presidente & 3 & 44 & 2 & 41 & 4 & 35 & 4 & 35 & 4 & 35 \\
\hline Vogal & 35 & 59 & 25 & 39 & 23 & 44 & 23 & 44 & 25 & 42 \\
\hline $\begin{array}{c}\text { Diretor } \\
\text { Clínico }\end{array}$ & 32 & 19 & 26 & 21 & 24 & 17 & 24 & 17 & 26 & 15 \\
\hline $\begin{array}{c}\text { Enfermeiro } \\
\text { Diretor }\end{array}$ & 31 & 16 & 23 & 18 & 20 & 19 & 20 & 19 & 19 & 20 \\
\hline Total & 101 & 138 & 76 & 119 & 71 & 115 & 71 & 115 & 74 & 112 \\
\hline
\end{tabular}

Fonte: Elaboração própria com base nas nomeações publicadas em Diário da República. 
Em 10 anos, num total de 993 nomeações, foram selecionadas 394 mulheres e 599 homens, o que representa $39,7 \%$ e $60,3 \%$. O ano em que foram nomeadas mais mulheres foi em 2006 (total de 101) e menos foi (2015).

A maioria das mulheres, na gestão hospitalar em Portugal, trabalha em Centros Hospitalares. Esta causalidade pode ser justificada pelo fato de existirem mais Centros Hospitalares ou pelo fato de estes apresentarem maiores dimensões e serem estruturas muito complexas (constituídas por vários hospitais). Por outro lado, são empregadas menos mulheres nas Unidades Locais de Saúde.

Quanto à distribuição das mulheres pelos cargos ocupados, se revela que, na maioria dos casos, elas são médicas ou enfermeiras que exercem as funções de diretora clínica ou enfermeira diretora, respectivamente. Em 39 presidentes do conselho de administração há apenas um máximo de quatro mulheres.

Outro fato interessante que se pode revelar nesta pesquisa é a questão de não existir um hospital apenas liderado por mulheres, ou, pior ainda, não se vê um conselho de administração com mais que uma mulher. Tendo por base $\mathrm{s}$ resultados obtidos nas tabelas apresentadas neste capítulo, foram realizadas as entrevistas semiestruturadas.

Quanto à primeira questão, foi questionada se existia desigualdade nas nomeações realizadas, entre 2006 e 2010. Cerca de 24 entrevistados (80\%) responderam que não há qualquer desigualdade no acesso a estes cargos de gestão que seja intencionalmente aplicada nas nomeações. Contudo, 6 (20\%) dos entrevistados responderam que sim, que há a tentação de prover uma desigualdade nas nomeações que privilegia os homens.

$\mathrm{Na}$ segunda pergunta, questionou-se quais os fatores que poderão justificar o fato de a maioria dos gestores nomeados pertencer ao gênero masculino. As respostas a esta questão foram muito variadas e cada entrevistado não se limitou apenas a dar uma opinião, pelo que no total se obtiveram 221 respostas. Aplicada a técnica da análise de conteúdo, foram definidas categorias e distribuídas as respostas em função das mesmas, obtendo-se os seguintes resultados:

- Os homens têm melhor currículo e mais experiência: 20 respostas $(9,0 \%)$;

- Os profissionais têm mais respeito por gestores homens: 25 respostas $(11,3 \%)$

- Os homens têm melhor capacidade de gestão: 6 respostas $(2,7 \%)$;

- As mulheres estão menos disponíveis para estes cargos: 28 respostas $(12,7 \%)$;

- As mulheres são esposas e mães e têm menor entrega para estes cargos: 30 respostas $(13,6 \%)$;

- É um cargo para homem pois exige muitas horas diárias: 30 respostas $(13,6 \%)$;

- Estes cargos levam trabalho para casa: 30 respostas $(13,6 \%)$;

- Os homens lidam melhor com o estresse: 22 respostas $(9,9 \%)$;

- As mulheres são líderes naturais: 15 respostas $(6,8 \%)$;

- Os homens são melhores gestores que as mulheres: 8 respostas $(3,6 \%)$;

- As mulheres são melhores gestoras que os homens: 7 respostas $(3,2 \%)$. 
$\mathrm{Na}$ resposta à terceira questão, $80 \%$ dos entrevistados referem que há uma forte influência política nas nomeações e $20 \%$ recusam essa influência. Na justificação da afirmação, referem que se trata de cargos de confiança que precisam estar ao lado do Governo para implementar corretamente as medidas planejadas. No entanto, outros referem que a avaliação curricular é importante e dão o exemplo do atual Governo que reconduziu os gestores com bons resultados de gestão e que contribuíram para a melhoria do acesso, eficiência e qualidade nos cuidados de saúde prestados em hospitais.

$\mathrm{Na}$ resposta à última pergunta, 17 dos 30 entrevistados referem que a CReSAP melhorou o recrutamento nos últimos três anos. No entanto, 13 indivíduos referem que não melhorou o recrutamento, pois, nestas nomeações, a CReSAP dá apenas um parecer sobre os nomes propostos e não faz a seleção e daí não controla as influências políticas, pessoais ou de gênero.

\section{Considerações Finais}

As desigualdades entre gênero foram sendo reduzidas ao longo dos anos nos países desenvolvidos e tem, assim, havido um notável progresso das mulheres. No entanto, em pleno século XXI ainda há relatos da sua existência.

Apesar dos progressos, as mulheres continuam a ocupar um determinado tipo de trabalhos (relacionados com a saúde, educação, serviços administrativos e serviços de limpeza, catering) e auferem de menor rendimento, o que perpetua a discriminação.

Em Portugal, o mercado de trabalho está praticamente equilibrado, com aproximadamente $49 \%$ de mulheres e $51 \%$ de homens. No entanto, existem muito mais mulheres em cargos intermédios e os homens lideram os cargos de topo, o que justifica a diferença média salarial que é superior nos homens. Este estudo teve como objetivo verificar se existe alguma discriminação de gênero nos altos cargos nomeados para a gestão hospitalar.

Assim, a exploração e a análise de dados relacionados com as nomeações para os cargos de gestão hospitalar, permitiram apurar uma desigualdade de gênero, mais de $60 \%$ dos nomeados são homens. Na perspectiva de compreender a base deste diferencial, foram efetuadas entrevistas cujas respostas confirmam que existe uma maior predisposição masculina para estes cargos que exigem uma grande entrega, o que impossibilita a admissão de mulheres que são esposas e mães. Portanto, no argumento dos inquiridos, em momento algum é colocada em causa a menor capacidade das mulheres ou a incapacidade para decidir e participar em cargos da gestão, apenas é apresentada uma construção social de que a estrutura dos profissionais de saúde têm um maior respeito por uma equipe de gestores constituída por homens.

Um grande desafio para as mulheres, de uma forma geral, é combater as desigualdades salariais ainda existentes entre homens e mulheres. No que diz respeito às mulheres gestoras, é tentar reverter este panorama das nomeações, demonstrando o seu entendimento nas matérias de liderança, gestão e de relação interpessoal. 
ABOIM, Sofia. A vida familiar no masculino: negociando velhas e novas masculinidades. Lisboa: Cite, 2010.

ABOIM, Sofia. Clivagens e continuidades de gênero face aos valores da vida familiar em Portugal e noutros países europeus. In: WALL, Karin; AMÂNCIO, Lígia. Família e gênero em Portugal e na Europa. Lisboa: ICS, 2007, p. 35 91.

AMÂNCIO, Lígia. Masculino e feminino: a construção social da diferença. Porto: Afrontamento, 1994.

BASTOS, Raul; MARQUES, Elizabeth; GALEAZZI, Irene; TONI, Miriam de; KRELING, Norma. Dimensão da Precarização do Mercado de Trabalho na Região Metropolitana de Porto Alegre. Porto Alegre: FEE, 2007.

BOURDIEU, Pierre. A dominação masculina. $2^{\mathrm{a}}$ edição. Rio de Janeiro: Bertrand Brasil, 2002.

CAMPOS, António Correia. Reformas da saúde - o fio condutor. Coimbra: Almedina, 2008.

CReSAP. Doze critérios de avaliação de um gestor/dirigente. Disponível em $<\mathrm{http}$ ://www.cresap.pt/cresap/criterios-de-avaliacao/doze-criterios-de-

avaliacao-de-um-gestor-dirigente.html>. Acedido a 2 de outubro de 2016 (2016a).

FERREIRA, Virgínia; MONTEIRO, Rosa; LOPES, Mónica; NETO, Hernâni; COELHO, Lina. Estudo de avaliação da integração da perspetiva do gênero nos fundos estruturais, no período de programação 2007-2013. Coimbra: IGFSE-CES, 2013.

HARFOUCHE, Ana. Opções políticas em Saúde. Coimbra: Almedina, 2012.

LONGO, Luciene. Uniões intra e interraciais, status marital, escolaridade e religião no Brasil: um estudo sobre a seletividade marital feminina, 1980 2000. 2011. Tese (Doutorado em Demogafia) - Universidade Federal de Minas Gerais, Belo Horizonte.

MONTEIRO, Rosa. Feminismo. In: SANTOS, Boaventura (Org.). Dicionário das crises e das alternativas. Coimbra: Almedina, 2012, p. $101-102$.

MONTEIRO, Rosa; FERREIRA, Virgínia. Planos para a igualdade gênero nas organizações: Contributo para o desenho e realização dos diagnósticos organizacionais. Revista Sociedade e Trabalho, n. 44, p. 123 - 136, 2013.

MONTEIRO, Rosa. O que dizem as mães: mulheres trabalhadoras e suas experiências. Coimbra: Quarteto, 2005. 
Desigualdades de Gênero nas Nomeações para Cargos de Gestão dos

Hospitais Portugueses no Período de 2006 a 2016

NUNES, Alexandre Morais. Gestão empresarial hospitalar na perspetiva dos gestores. Lisboa: Instituto Superior de Ciências Sociais e Políticas, 2013.

NUNES, Alexandre Morais. Reformas na Gestão hospitalar: análise dos efeitos da empresarialização. Lisboa: Instituto Superior de Ciências Sociais e Políticas, 2016.

OAKLEY, Ann. Sex, gender and society. Londres: Temple Smith, 1972.

PERNAS, Gonçalo; FERNANDES, Manuel; GUERREIRO, Maria. D. Guião para a implementação de planos de igualdade na administração pública local. Lisboa: ISCTE/CIG, 2008.

RATO, Helena; MADUREURA, César; ALEXANDRE, Helena; RODRIGUES, Miguel; OLIVEIRA, Teresa. A igualdade de gênero na administração pública central portuguesa. Lisboa: Instituto Nacional de Estatística/Fundação para a Ciência e Tecnologia, 2007.

SANTOS, Gina. Gestão, trabalho e relações sociais de gênero. In: FERREIRA, Virgínia (Org.). A igualdade de mulheres e homens no trabalho e no emprego em Portugal: políticas e circunstâncias. Lisboa: Cite, 2010, p. 99 138. 